double-base forms with a corresponding one by P. Tavernier and J. Boisson (France) on composite forms and one on burning rate control by G. H. Young (Great Britain). All these appeared to suffer from the limitations imposed by 'security', but the first two gave useful accounts of the standard materials and processes in manufacture. It was interesting to compare these and from this point of view they were an informative contribution. Steinberger, howover, included a good deal more on the life expectancy of double-base propellants. This is not surprising in view of the much longer experience of them which exists. The paper by Young covered some of the same ground and, rather than a discussion of burning rate control, was limited to descriptions of methods of measuring burning rate and the range of burning rates achieved. The difficulties imposed on this author by the classified nature of his subject were obvious and it was generally agreed that it could only receive suitable treatment at a closed session.

The papers on air-burning fuels included one on properties and preparation of ramjet fuels by M. Barrere and G. Français (France), one on performance evaluation by $\mathrm{E}$. Porchonok (United States), one on deposits in jet engines by $R$. Breit wieser (United States) and a final one on physicochemical reactions during nozzle flow by J. F. Morris (United States). The first two covered the main features found necessary in the special conditions of ramjet operation and collected much data which will be useful for future reference. Both papers dwelt on the use of solid fuels in slurry form and the attractions of boron hydrides and other compounds, but the American paper emphasized some additional considerations if ramjets are to be operated at hypersonic speeds. For example, the need for regenerative cooling of engine walls will limit the use of $J P-4$ fuel to speeds of $M=6$. The high gas temperatures resulting from these speeds also have an important effect on dissociation conditions and thrust available. With frozen gas exit flow, the thrust may be reduced as much as 58 per cent at $M=8$, compared with equilibrium flow. This problem was treated by Morris, who reviewed the background of relaxation rate-theory and discussed the gaps in knowledge which will enable predictions of non-equilibrium flow of both internal and external gas for hypersonic vehicles. The long list of references appended to this paper calls for special mention as it extends to more than four hundred. The other paper in this group emphasized the problems of solid deposits in engines and pointed out that these became more serious with some of the high-energy fuels now being considered. Boric oxide is one combustion product which may form on engine surfaces in large quantities. Some measurements on convergent-divergont nozzles showed losses in total stream momentum of more than 5 per cent within 20 sec. of initiating combustion. Other sensitive components are turbine stator blades and combustion chambers. Two mechanisms of deposition were discussed, consisting of diffusion of particles less than $\frac{1}{2} \mu$ diameter, and of impact by particles of $5 \mu$ and larger. The former was analysed theoretically and compared with measured deposition rates. Although good agreement was claimed, this analysis received some criticism during the discussion.

In addition to the papers, a round table discussion on basic problems in propulsion was held with Dr. von Karman in the chair. The discussion was initiated by A. D. Baxter (Great Britain), who summarized the merits of liquid propellant rocket engines and outlined some of the remaining lines which require research. These included physical problems such as heat transfer and combustion chamber design parameters, and chemical problems associated with propellant stability, ignition delays and reaction rates. H. W. Ritchey (United States) then presented a similar case for solid propellants and was followed by three speakers giving views on futuristic possibilities. G. B. Kistiakowsky (United States) spoke on solid propellant horizons, J. W. Bond (United States) on electromagnetic and nuclear thermal propulsion, and A. Ferri (United States) on composite launchers. The last was a stimulating argument in favour of air breathing engines as the first stage in multi-stage rocket vehicles. One of the advantages would be the ability to fit aerodynamic lifting surfaces and fly the launcher back to the take-off point. The discussion was so successful that it was continued at the final session of the meeting, ranging over a broad field. Points brought out were the convergence of design features in solid-and liquid-propellant engines, the question as to how vital improved specifie impulse was, the problems of size in rockets and the future of nuclear rockets.

This discussion was a fitting climax to a successful meeting and no doubt, when the edited proceedings are published, they will be found to provide a valuable addition to the literature, not only because of the data included, but equally because of the excellent bibliographies attached to most papers. A. D. BAXTER

\title{
CLAY MINERALS
}

T TWO series of meetings on clay minerals were held in Yorkshire during April. The first, at Shefficld, was arranged by the Clay Minerals Group of the Mineralogical Society. Two sessions on April 15, in the Metallurgy Department of the University, were devoted to the reading of scientific papers, while on April 16 visits were made to the works of Thomas Marshall at Loxley and General Refractories at Wharncliffe. The chair at the scientific sessions was occupied by Dr. A. F. Hallimond (London), chairman of the Group, in the morning, and by Prof. J. White (Sheffield) in the afternoon.

Several papers concerned the industrial application of clay mineralogy. In the first of these, E. $H$.
Steger (London) discussed various problems in civil engineering in which clays are implicated, and dealt particularly with soil stabilization by injection of a suitable clay suspension into sands, etc. The factors necessary to give good results are broadly known, but much work on fundamental aspects is still required. In the discussion, the difficulty of replicating laboratory findings in the field was widely referred to.

Divergent views upon the relationship between the mineralogical constitution and the firing properties of clays were expressed by Prof. G. W. Brindley and S. Udagawa (Pennsylvania) and by Dr. R. W. Nurse (Watford). The former described how, by 'synthesizing' clays from mixtures of appropriate pure 
minerals over a range of compositions, it is possible to make some forecasts regarding the behaviour of natural clays from a rapid check of their mineralogical composition. This technique enables immediate rejection of completely unsuitable clays, but those which appear of possible use still have to be tested individually. Dr. Nurse, on the other hand, could find no correlation between firing properties and mineralogical composition for a series of clays of various geological ages.

The use of thermal expansion measurements in indicating the mineralogy of clays ${ }^{1}$ was considered by D. A. Holdridge (Stoke-on-Trent), who showed its application in quartz determinations. The significance of the same test after firing was also diseussed.

Dr. R. F. Youell (Leeds) described how X-ray data on heat-treated silicates, which he had obtained earlier, were explicable on the basis of siliconcontaining spinel structures ${ }^{2}$. He particularly referred to the composition of the spinel phases and the occurrence of ordered transformations. In discussion, the propriety of using the term 'silicate' for a siliconcontaining spinel was questioned and the frequency of occurrence of ordered transformations was stressed.

Three general papers were also read. In the first B. D. Mitchell and Dr. R. C. Mackenzie (Aberdeen) described a relatively inexpensive controlled-atmosphere differential thermal analysis apparatus and illustrated its applicability to investigations in nitrogen, oxygen and steam, while in the other two Dr. H. G. Midgley (Watford)-this paper was read in his absence by Dr. R. W. Nurse-and W. Windle and E. K. Cundy (St. Austell) described occurrences of sepiolite and zinnwaldite, respectively, in Cornwall ; chemical, X-ray and other data were given.

This meeting not only brought to notice relatively new uses of clays in industry (such as their use in soil stabilization) but also raised the practical question of the value of mineralogical analysis in assessing clays. Difficulties encountered in relating the mineralogy of a clay to its firing properties could, for example, be due either to incomplete mineralogical data or to effects being not truly additive: the observations reported rather suggest the latter.

The Sheffield meeting was followed by one at Leeds during April 17-18 arranged by the X-ray analysis Group of the Institute of Physies. This meeting included a session on clay minerals as well as one on biological fibres; only the former is reported here.

No outstanding advance in structural investigations of the common natural clay minerals was fortheoming at the meeting. Prof. G. W. Brindley, in an introductory address, pointed to the value of electron diffraction techniques in such investigations. He wes able to report a very promising approach to the problem of thermal changes in kaolinite by his collaborator, M. Nakahira, using small single crystals. This work suggests that the 'spinel' phase is really a silica-alumina crystallization structurally similar to spinel $^{2}$, and appears to have furnished clear evidence that the much-discussed metakaolin is not amorphous, but is an intermediate stage in the formation of spinel, having a substantial degree of crystallinity.

The dehydration products of kaolinite were also discussed by F. Vaughan (Stoke-on-Trent). D. A. Holdridge showed the possibilities of thermal expansion measurements for studying phase changes on firing. Quartz content, notably, can be estimated by this means.

Interesting structural studies on scarbroite were reported by Dr. J. Goodyear and Dr. W. J. Duffin (Sheffield) and on iddingsite by G. Brown and Dr. I. Stephen (Harpenden). H. P. Rooksby (Wembley) reported on further detailed work on iron and aluminium oxides.

The question of surface structure in clays is one of fundamental importance, about which there is still much uncertainty. An extensive, many-sided approach to this problem is being made by Prof. J. J. Fripiat and collaborators in Belgium under the auspices of Institut National pour 1'Études Agronomiques $d u$ Congo Belge. Among the techniques under study are measurement of surface hydroxyl groups by exchange with heavy water vapour, and methylation and acetylation for determining acidic groups.

Dr. D. M. C. MacEwan (Dundee) reported on an extensive series of calculations on diffraction effects from mixed-layer structures, now being carried out with electronic calculators. The resulting curves will be published as a special monograph by the Spanish Consejo Superior de Investigaciones Cientificas,

Study of a German 'fireclay mineral' by Prof. A. L. Roberts and Dr. W. E. Worrall (Leeds) provided further support for Schofield's theory of the existence of isomorphous substitution in kaolins.

R. C. MACKENZIE

D. M. C. MacEwan

${ }^{1}$ ef. Brough, J., and Robertson, R. H. S., Clay. Min. Bull., 3, 221 $(1958)$.

${ }^{2}$ Steadman, R., and Youell, R. F., Nature, 180, 1066 (1957). Brindley,

G. W., and Nakahira, M., Nature, 181, 1333 (1958).

\section{THE COUNCIL FOR SCIENTIFIC AND INDUSTRIAL RESEARCH}

$\mathrm{T}$ HE second report of the Council for Scientific and Industrial Research covers the year 1958 in which the Department's gxoss expenditure was $£ 9,453,652$, compared with $£ 8,255,561$ in the previous year, and reduced to $£ 8,357,913$ by various receipts (£464,713 being from the National Physical Laboratory) for work done for Government departments or for industry, the net increase on 1957 being $£ 1,108,070$. Grants to students amounted to $£ 444,958$, the number of students in training being 1,681 and in 1957, 1,301, of whom 781 in 1958 and 653 in 1957 were now. The advanced course studentships increased from 152 in 1957 to 201 , of which 184 were new, and of 26 research fellowships (18 in 1957), 14 were new. Grants for special researches totalled $£ 475,754$, numbering 239 compared with $£ 363,884$ and 193 in 1957 , and of these 147 were new. Of these grants 106 were in physies, 45 in chemistry, 32 in biology and biochemistry, 24 in other engineering, 11 in geology, 7 in mathematics, 6 in chemical engineering and metallurgy, and 3 in electrical engineering. Chemistry claimed 593 of research students, physics 360 , biology and biochemistry 208, mathematics 144, chemical engineering and metallurgy 110 , other engineering 100 , geology 99, electrical engineering 50, and human sciences 17 . 